\title{
Genome-wide analysis of RopGEF gene family to identify genes contributing to pollen tube growth in rice (Oryza sativa)
}

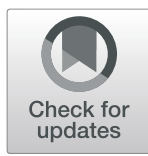

\author{
Eui-Jung Kim ${ }^{1 \dagger}$, Sung-Wook Park' ${ }^{1 \dagger}$, Woo-Jong Hong ${ }^{1}$, Jeniffer Silva' ${ }^{1}$, Wanqi Liang ${ }^{2}$, Dabing Zhang ${ }^{1,2}$, \\ Ki-Hong Jung ${ }^{1 *}$ and Yu-Jin Kim ${ }^{1 *}$ (D)
}

\begin{abstract}
Background: In plants, the key roles played by RopGEF-mediated ROP signaling in diverse processes, including polar tip growth, have been identified. Despite their important roles in reproduction, a comprehensive analysis of RopGEF members has not yet been performed in rice (Oryza sativa). To determine whether RopGEF regulators are involved in rice pollen tube growth, we performed genome-wide analysis of this family in rice.

Results: Phylogenomic and meta-expression analysis of eleven RopGEFs in rice showed that four genes were preferentially expressed in mature pollen. These four genes contain the plant-specific Rop nucleotide exchanger (PRONE) domain and possible phosphorylated residues, suggesting a conserved role in polar tip growth with Arabidopsis thaliana. In subcellular localization analysis of the four RopGEFs through tobacco (Nicotiana benthamiana) infiltration, four proteins were predominantly identified in plasma membrane. Moreover, double mutants of RopGEF2/8 exhibited reduced pollen germination, causing partial male sterility. These genes possess unique cis-acting elements in their promoters compared with the other RopGEF genes.

Conclusions: In this study, four RopGEF genes were identified as pollen-specific gene in eleven members of rice, and the expression pattern, promoter analysis, and evolutionary relationship of the RopGEF family were studied compared with Arabidopsis. Our study indicated that four RopGEF genes might function during pollen germination in distinct subcellular localization. Our study could provide valuable information on the functional study of RopGEF in rice.
\end{abstract}

Keywords: RopGEF, ROP/Rac, Pollen, Oryza sativa, Gene family

\section{Background}

Rho-type GTPases of plants (ROP), also known as RACs, are a plant-specific subfamily of Rho small GTP-binding proteins [1] and participate in diverse signal transduction processes, including disease resistance, pollen tube growth, root hair development, reactive oxygen species (ROS) production, cell wall

\footnotetext{
*Correspondence: khjung2010@khu.ac.kr; yujinkim@khu.ac.kr

${ }^{\dagger}$ Eui-Jung Kim and Sung-Wook Park contributed equally to this work.

'Graduate School of Biotechnology and Crop Biotech Institute, Kyung Hee University, Yongin 17104, South Korea

Full list of author information is available at the end of the article
}

patterning, and hormone responses [2]. Similar to Rho family proteins in other eukaryotic cells, ROPs regulate endocytosis and exocytosis through cytoskeleton organization and intracellular kinase cascades through activation of NADPH oxidase, processes that are key for cell polar growth in plants [3-6]. Activation and inactivation of ROP, by change in its conformation following GTP binding and hydrolysis (GDP-binding form), functions as a molecular switch in signal transduction [6, 7]. Conversion from the GDP and GTP form of Rho GTPases is catalyzed by

(c) The Author(s). 2020 Open Access This article is licensed under a Creative Commons Attribution 4.0 International License, which permits use, sharing, adaptation, distribution and reproduction in any medium or format, as long as you give appropriate credit to the original author(s) and the source, provide a link to the Creative Commons licence, and indicate if changes were made. The images or other third party material in this article are included in the article's Creative Commons licence, unless indicated otherwise in a credit line to the material. If material is not included in the article's Creative Commons licence and your intended use is not permitted by statutory regulation or exceeds the permitted use, you will need to obtain permission directly from the copyright holder. To view a copy of this licence, visit http://creativecommons.org/licenses/by/4.0/. The Creative Commons Public Domain Dedication waiver (http://creativecommons.org/publicdomain/zero/1.0/) applies to the data made available in this article, unless otherwise stated in a credit line to the data. 
guanine nucleotide exchange factors (GEFs). Plantspecific RopGEFs spatiotemporally regulate the activity of ROPs/Racs through the catalytic plant-specific ROP nucleotide exchanger (PRONE) domain [8].

Although few studies of RopGEFs have been carried out in other plant species, recent studies in the model plant Arabidopsis support their roles in various plant development processes as well as in defense. Arabidopsis has 14 RopGEFs in its genome, with a high degree of sequence similarity $[8,9]$. Functional studies showed that AtRopGEF1 and AtRopGEF4 specifically regulate ROP11 in abscisic acid (ABA)-mediated stomatal closure [10], and that AtRopGEF1 plays a role in controlling lateral root growth [11] and polar auxin transport to achieve cell polarity during early plant development [12]. Among them, seven members are specifically or highly expressed in pollen tubes and function redundantly $[8,13]$. Pollen-specific RopGEFs have conserved C-termini, which function by autoinhibition of the PRONE domain [13]. Recent findings suggest that pollen-specific receptor-like kinases (PRKs) transduce ROP signaling via phosphorylation of RopGEFs at the C-terminus to regulate polar pollen tube growth [13-17]. Germinated pollen tube enters the female gametophyte and delivers sperm cells to egg cells and polar central cells, which perform double fertilization in flowering plants [18]. When some ligands are received by receptor-like kinases (RLK), RopGEFs are activated and convert GDP to GTP, which binds to ROP [19]. AtPRK2 promotes ROP1 via phosphorylation of RopGEFs in the control of polarized pollen tube growth [16]. Interaction of AtPRK6 with AtRopGEF8 and AtRopGEF12 plays essential roles in polarized growth of pollen tubes [17]. Another RLK, FERONIA, belonging to the Catharanthus receptor-like kinase (CrRLK) family, was shown to function as an upstream regulator of RopGEFs, mediating auxin efflux on root hair growth in Arabidopsis [20-22].

In rice (Oryza sativa), among the first 12 reported genes, 11 OsRopGEFs encoded full-length proteins [23]. OsRopGEFs were shown to play a role in the activation of OsRac1 in the disease-resistance response [24]. OsRac1 negatively regulates cell death and innate immunity by production of ROS $[25,26]$. It was shown that OsRac1 activates plant NADPH oxidase, known as OsRbohB (respiratory burst oxidase homolog), by direct interaction [27]. In addition, OsRopGEF10 activates the development of small cuticular papillae on leaf surfaces [28], whereas OsRopGEF7B is involved in regulating floral organ development [29]. Compared with Arabidopsis, the molecular function of rice RopGEF members in response to plant developmental cues is poorly understood.
To reveal whether roles in polar tip growth in rice exist for the conserved RopGEFs, we investigated in the present study the phylogenetic relationship of rice and Arabidopsis RopGEF proteins, analyzing the PRONE domain and characterizing the amino acid residues. The molecular mechanism on rice pollen tube growth is less known, in spite of its importance on gamete transmission for successful reproduction [30]. We identified four pollen-preferred OsRopGEF genes through meta-expression analysis using our pollen/anther database, followed by confirmation by qRT-PCR. In addition, we performed subcellular localization of each RopGEF through tobacco infiltration and cis-acting element (CRE) analysis of the four pollen-preferred OsRopGEF genes, revealing a conserved CRE. Finally, we generated and analyzed single and multiple knock-out mutants for the functional studies.

\section{Results}

\section{Expression profiling analysis of RopGEF genes}

To identify the pollen-preferred genes of rice, we examined a publicly available Affymetrix rice microarray data [31]. Expression patterns conserved between indica and japonica rice varieties at various developmental stages of anthers and pollen, and anatomical meta-expression data from our established database, Rice Anther Pollen Expression Database (RAPED) (http://ricephylogenomicskhu.org/RAPED/home.php), were analyzed. We then constructed a phylogenic tree by aligning the protein sequences of all OsRopGEFs. Meta-expression data in the context of the phylogenetic tree were combined to check the function of OsRopGEFs with respect to anther and pollen development, compared with other tissues/organs (Fig. 1a). As a result, the rice RopGEF gene family can be divided into two subfamilies, one group to which OsRopGEF2, 3, 4, 6, and 8 belong, and the other to which the remaining six genes belong, namely OsRopGEF1, 5, 7, 9, 10 , and 11 .

In addition, we identified that OsRopGEF2, OsRopGEF3, OsRopGEF6, and OsRopGEF8 showed selective expression at the stage of late pollen development, i.e., at stages of tricellular pollen grains, mature pollen (MP), and germinated pollen (GP). These four genes were used for further analyzes. Since OsRopGEF3 was also highly expressed in root hairs, we predicted that this gene could affect tip growth (Additional file 1). Genes OsRopGEF4 and OsRopGEF7 showed some expression in the early stages of anther development, although their expression levels decreased during the later stages. Furthermore, because expression is also detected in tissues other than anther and pollen, these two genes cannot be considered to be pollen-preferred expressed genes. In addition, OsRopGEF5 showed weak expression in 


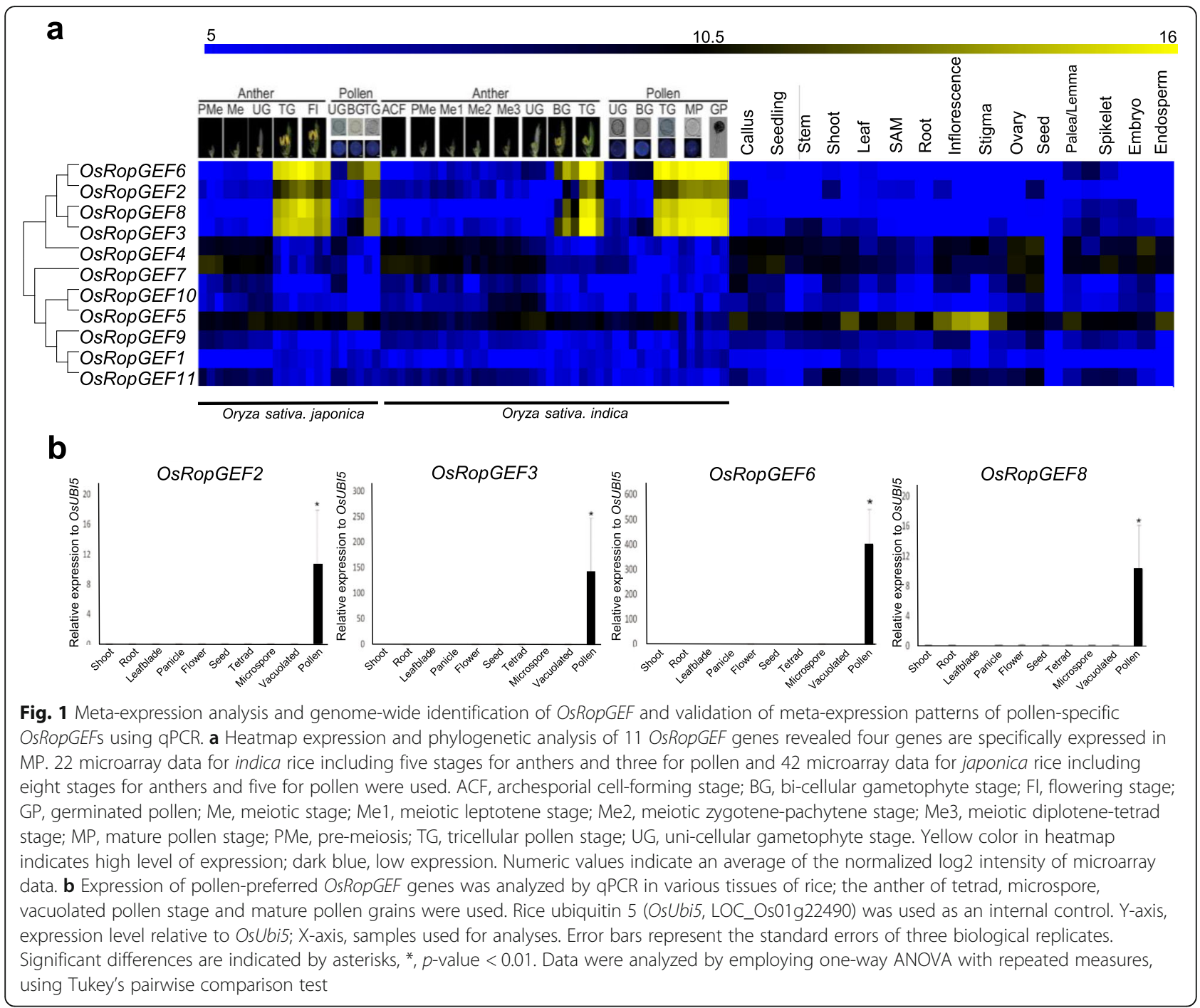

japonica rice anthers and other tissues, showing no preferred expression in anthers and pollen.

Next, to verify the meta-expression data, we performed quantitative real-time PCR (qPCR) using ten tissues: shoot, root, leaf blade, panicle, flower, seed, tetrad microspore, young microspore, vacuolated pollen, and MP (Fig. 1b). By sampling anthers at various developmental stages, from pollen mother cell to MP and GP, we tried to determine at which stage the target genes were being expressed. As a result, OsRopGEF2, OsRopGEF3, OsRopGEF6, andOsRopGEF8 were shown to be highly expressed in MP. OsRopGEF6 showed the highest level of expression in MP, and OsRopGEF2 and OsRopGEF8 showed similar expression levels in MP. These native pollen-preferred OsRopGEFs were generally not expressed in other tissues, similar to meta-expression profiles using microarray data. Especially in rice, gene expression profiles of mature and germinated pollen were highly correlated [31]. Therefore, these four genes may play key roles in pollen tube growth and other processes that occur after pollen maturation.

\section{Comparative analysis of the conserved domains in RopGEF genomic and protein sequences between rice and Arabidopsis}

Genes OsRopGEF2, OsRopGEF3, OsRopGEF6, and OsRopGEF8 encode proteins with similar amino acid sequences. RopGEFs are considered to be a novel gene family with a unique structure containing the PRONE catalytic domain that is exclusively found in the plant RopGEF gene family [9]. The PRONE domain is known to be required for RopGEFs to convert GDP to GTP. The PRONE domain of RopGEFs is highly conserved in all OsRopGEFs. More interestingly, the pollen-preferred OsRopGEFs were found to retain the C-terminus region after the PRONE domain (Fig. 2b), whereas the pollennon-preferred OsRopGEF1, OsRopGEF9, and OsRopGEF11 lack this C-terminus. 

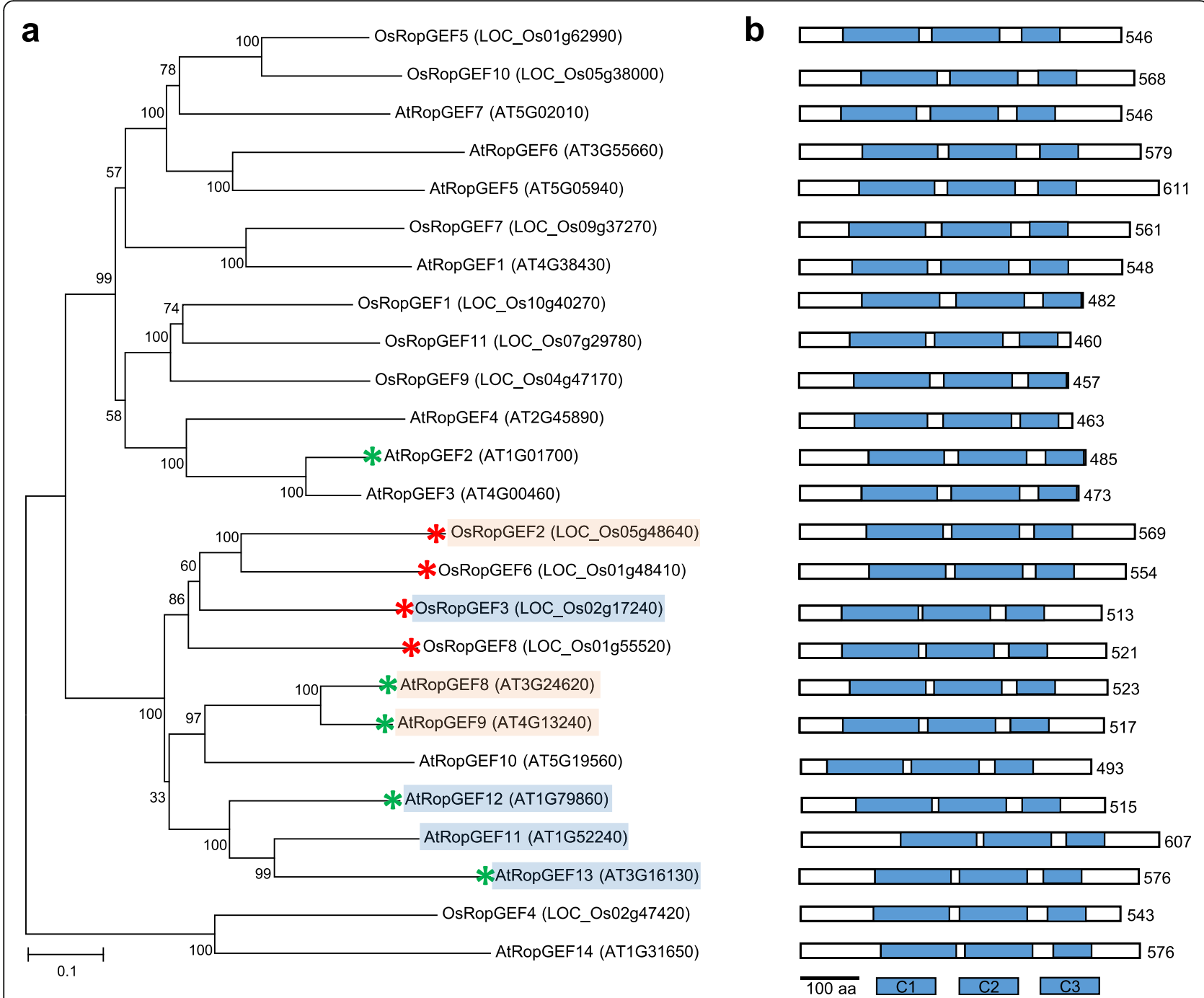

Fig. 2 Phylogenetic analysis of RopGEF family from Oryza sativa and Arabidopsis thaliana. a The phylogenetic tree was constructed by annotating the protein sequences for each gene by using MEGA7. Protein sequence alignment was performed by ClustalW and phylogeny by Neighborjoining methods, with the reliability being estimated by the 1000 times bootstrap test. The number between the trees represents the bootstrap value. Os, Oryza sativa; At, Arabidopsis thaliana. Red and green asterisks indicate RopGEF genes with high expression in pollen in O. sativa (in this study) and Arabidopsis thaliana [8], respectively. Red and blue boxes indicate the orthologous relation between rice and Arabidopsis RopGEF genes indicated in RGAP. $\mathbf{b}$ A scheme of protein structure. We arranged the sequence of the protein domain scheme to be the same as the gene sequence of the phylogenetic tree of A. Length of each RopGEF protein is shown on the right and its unit is aa (amino acid). C1, C2, and C3 (blue boxes) indicate position and length of the conserved PRONE subdomain of the RopGEF family

For the comparative analysis of RopGEF gene families, we collected the protein sequences of 14 AtRopGEFs and 11 OsRopGEFs and constructed a neighbor-joining tree (Fig. 2a). Four OsRopGEF genes showing pollenpreferred expression were clustered together with AtRopGEF8 and 9, which also exhibited pollen-preferred expression. In the Arabidopsis RopGEF family, the expression patterns revealed by qPCR were not consistent with those from previous reports: AtRopGEF1, 8, 9, 12, 14 were detected in pollen tissues [8] and AtRopGEF8, 9, 10,11 , and 13 showed pollen-preferred expression, respectively, and, of these, the latter data corresponded more closely with the transcriptome data in Genevestigator (Additional file 2). According to Rice Genome Annotation Project (RGAP, http://rice.plantbiology.msu. $\mathrm{edu} /$ ), the orthologs for OsRopGEF2 are AtRopGEF8 and AtRopGEF9, and those for OsRopGEF3 are AtRopGEF11, AtRopGEF12, and AtRopGEF13. However, the orthologs for OsRopGEF6 and OsRopGEF8 have not been identified. In the phylogenetic tree, rice members with pollenpreferred expression were closely clustered with those in Arabidopsis and the C-terminal amino acid sequences were more similar than those for other members in rice. The invariant serine residue (S510, numbered as in 
AtRopGEF12) within the C-terminus, which is important for C-terminal inhibition [13] was also located in pollenpreferred RopGEF members in rice (Additional file 3), supporting the hypothesis that phosphorylationregulated GEF activity was conserved.

\section{Protein structure}

Protein sequence analysis and hydropathy plot profiling revealed that AtRopGEF and OsRopGEF, both with pollen-preferred expression, had mostly similar amino acid sequences but differed at the $\mathrm{N}$ - and C-termini (Fig. 3). The analyzed rice RopGEF 3-D models exhibit a butterfly-shaped three-dimensional structure in which two PRONE protomers dimerize via their $\mathrm{N}$-terminal groups (Fig. 4). Each protomer consisted of two subdomains, with the subdomain 1 containing the WW-loop, which is a common characteristic in Arabidopsis [7] (Table 1). To more precisely characterize the 3-D model structures, we compared the pollen-preferred rice RopGEF 3-D models with those from Arabidopsis. The subdomains differed in the number of alpha helices and the number of residues in the WW-loop between the OsRopGEFs and the AtRopGEFs. Rice and Arabidopsis RopGEF 3-D models displayed trends in the number of $\alpha$-helices from 14 to 17 , and in the number of residues in the WW-loop from 25 to 50.

OsRopGEFs contained 14 to 15 alpha helices, and 25 to 40 residues in the WW-loop, whereas AtRopGEFs contained 14 to 17 alpha helices, and 38 to 50 residues in the WW-loop. The main difference between OsRopGEFs and the reported AtRopGEF [32] is in the WWloop, where AtRopGEF displayed $\alpha$-helices or betastrands in the WW-loop, whereas OsRopGEFs did not contain $\alpha$-helices or beta-strands.

\section{Subcellular localization of four RopGEF proteins}

The RopGEF is known to regulate ROP signaling in the plasma membrane (PM). Arabidopsis RopGEF8, RopGEF9, and RopGEF14 were shown to be localized to the apical PM of the pollen tube, and RopGEF1 to the entire PM. On the other hand, RopGEF12 was barely detected in the PM, being present in the cytosol of the pollen tube [8], suggesting that the different localizations of RopGEF in pollen tubes represented differences with respect to multiple regulatory ROP signaling actions. Therefore, we examined the subcellular localization of OsRopGEF members to check whether their spatial locations were the same or different. We introduced

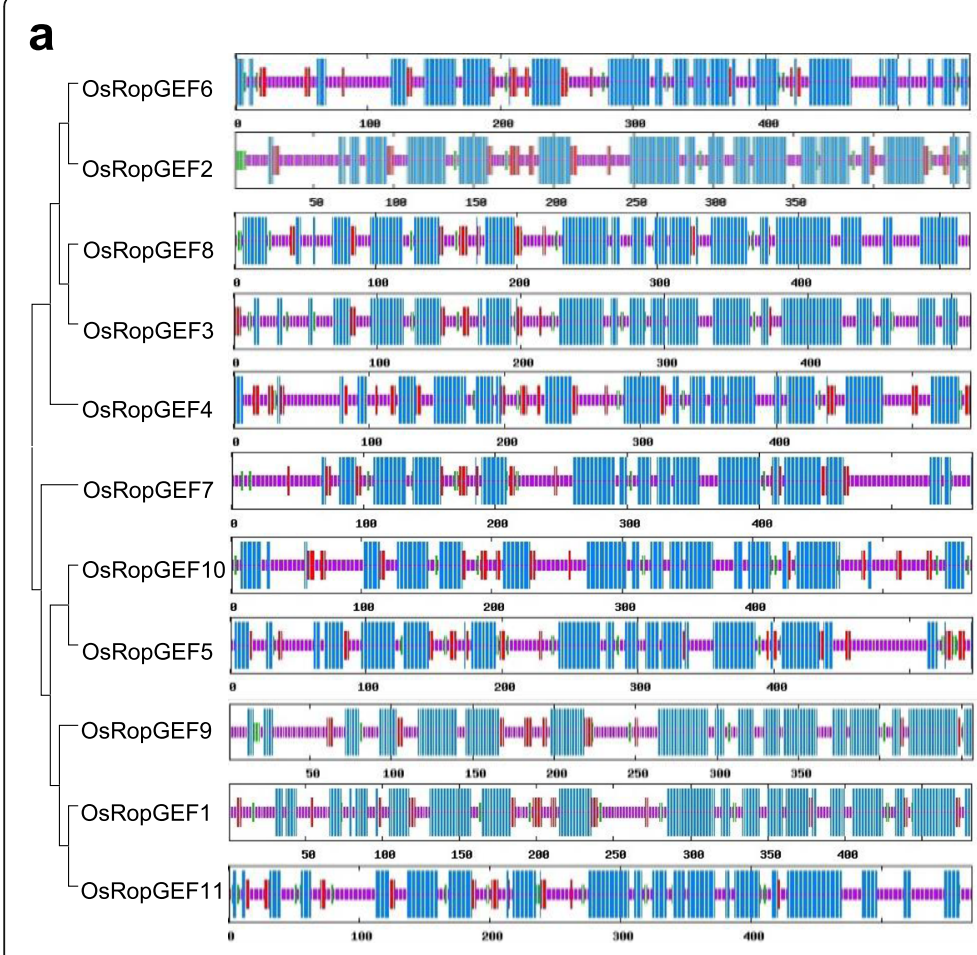

b

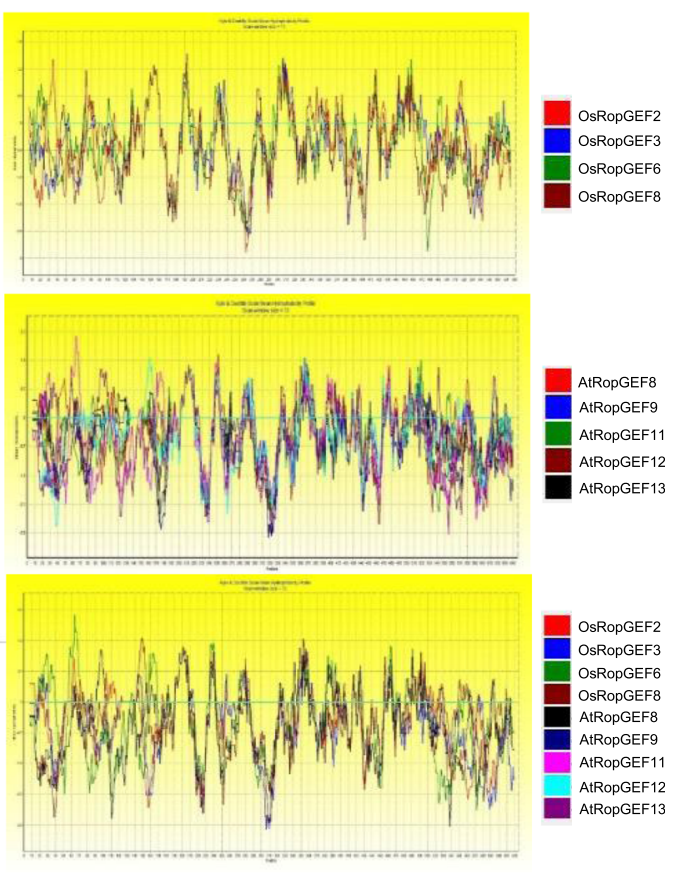

Fig. 3 Protein sequence analysis. a Secondary structure of RopGEF using the deduced amino acid sequences from OsRopGEFs. Blue lines indicate alpha helices, purple lines indicate random coils, red lines denote extended strands, and green lines represent beta turns. b Hydropathy plot analysis. The upper part of the figure is the hydropathy plot of four OsRopGEFs which showed pollen-specific expression, and the central part is a hydropathy plot of five AtRopGEF genes that are pollen-specific expressed in the Genevestigator. The last figure is the sum of four OsRopGEF and five AtRopGEF hydropathy plots. Profiles of rice and Arabidopsis RopGEFs showed similarities in the PRONE domain, but not for the $\mathrm{N}$ and C-termini 


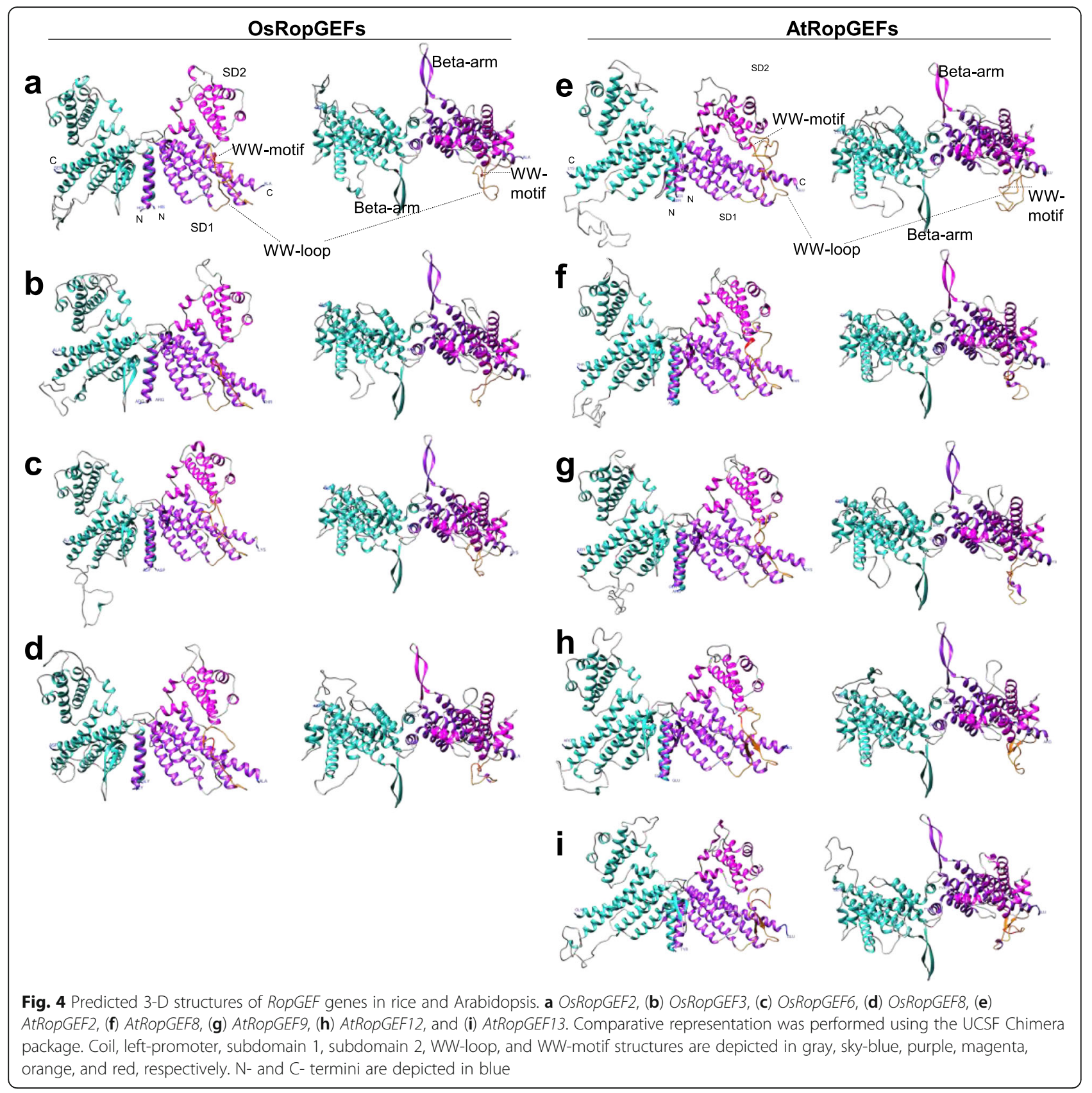

RopGEF-GFP fusion proteins controlled by the Cauliflower mosaic virus (CaMV) $35 \mathrm{~S}$ promoter into the epidermal cells of tobacco leaves, and empty GFP protein was used as a control. The GFP signals of four RopGEF genes were observed in the PM. Further, we used FM464 staining as a membrane marker to confirm how the membrane marker and the GFP signal of RopGEF protein correlate (Fig. 5). Control GFP signals were present in the nucleus, membrane and cytosol inside membrane (Fig. 5a-d). Most of the RopGEF protein signals are well merged with the FM4-64 stained RFP signal (Additional file 4). OsRopGEF6 were specifically localized into the PM, consistent with the common RopGEF location (Fig. $5 \mathrm{~m}$-p), while the GFP signals of OsRopGEF2, OsRopGEF3 and OsRopGEF8 were predominantly found in the cytosol as well as in the PM (Fig. 5i-l). The GFP signal of OsRopGEF2, located in the cytosol, was seems like associated with the endoplasmic reticulum, rather than the nucleus (Fig. 5e-h) [33], while the OsRopGEF8 signal was associated with the nucleus (Fig. 5q-t) [34]. The results suggest that the four pollen-preferred members of OsRopGEF could carry out unique functions during pollen germination, as reflected by their distinct subcellular locations. 
Table 1 Characteristics of 3D predicted model RopGEFs of rice and Arabidopsis

\begin{tabular}{llllll}
\hline Gene & $\begin{array}{l}\text { Number of } \\
\text { alpha helices }\end{array}$ & $\begin{array}{l}\text { Number of residues } \\
\text { in WW-loop }\end{array}$ & $\begin{array}{l}\text { Subdomain 1 } \\
\text { alpha helices }\end{array}$ & $\begin{array}{l}\text { Subdomain 2 } \\
\text { alpha helices }\end{array}$ & Observations \\
\hline OsRopGEF2 & 15 & 40 & $1-6,15$ & $7-14$ & - \\
OsRopGEF3 & 14 & 34 & $1-6,14$ & $7-13$ & - \\
OsRopGEF6 & 15 & 40 & $1-6,15$ & $7-14$ & - \\
OsRopGEF8 & 15 & 25 & $1-7,15$ & $8-14$ & - \\
AtRopGEF2 & 14 & 50 & $1-6,14$ & $7-13$ & - \\
AtRopGEF8 & 16 & 40 & $1-8,16$ & $9-15$ & WW-loop contains two alpha helices $(6,7)$ and the WW- \\
& & 40 & $1-7,15$ & $8-14$ & motif is embedded in alpha-helix 6 \\
AtRopGEF9 & 15 & 38 & $1-7,14$ & $8-13$ & WW-loop contains two alpha helices $(5,6)$ \\
AtRopGEF12 & 14 & 40 & $1-7,17$ & $8-16$ & WW-loop contains two beta-strands \\
AtRopGEF13 & 17 & & & & WW-loop contains two beta-strands \\
\hline
\end{tabular}

\section{Promoter analysis of pollen-preferred genes}

Up to now, the information about the roles of transcription factors and regulatory motifs in pollen germination in rice has been unclear. Based on the microarray data and the qPCR results, we performed a promoter analysis to identify the cis-elements conserved in the promoters of OsRopGEFs associated with pollen-preferred expression.

We searched the known cis-regulatory elements (CREs) in the promoter based on existing research (Additional file 5). Major pollen-preferred CREs such as POLLEN1LELAT52 (AGAAA), PB Core (CCAC), and GTGANTG10 (GTGA) [35] were identified. In the case of POLLEN1LELAT52, 12 CREs existed in the OsRopGEF3 promoter and seven CREs existed in the OsRopGEF8 promoter. In the case of GTGANTG10, 11 CREs existed in the OsRopGEF8 promoter. In the case of the PB Core, there were five copies in the OsRopGEF2 promoter, and four copies in each of the OsRopGEF6 and OsRopGEF8 promoters. However, in the case of the remaining OsRopGEF family genes, there were also many pollen-preferred CREs present in the promoters of genes which exhibited little or no expression in pollen. On average, there were 4.3 copies of POLLEN1LELAT52, 6.4 copies of GTGANTG10, and 1.6 copies of the PB Core in the promoters of the seven OsRopGEFs compared with the four highly pollen-preferred genes. We calculated the $p$-values to determine how many of the four highly pollen-expressed OsRopGEF genes had significantly more CREs relative to the rest of the OsRop$G E F$ genes, but all did not exceed 0.01. Based on these results, we assume that known pollen CREs do not regulate the expression of the four pollen-preferred OsRopGEFs.

We then searched to find CREs that existed in the promoters of only pollen-preferred OsRopGEFs. Firstly, we searched for motifs that were common to the promoters of the four pollen-preferred genes, using MEME (Fig. 6). We downloaded the 2000-base pair upstream sequences of the four OsRopGEF genes and found ten conserved elements. Among them, three CREs were absent from the promoters of the other, pollen-non-preferred OsRopGEF genes. These three CREs were present at -2000 to $1500 \mathrm{bp}$ from the transcription start sites of OsRopGEF3 and OsRopGEF6, and mainly existed within - $1000 \mathrm{bp}$ of the transcription start sites of OsRopGEF2 and OsRopGEF8. All CREs were present once in the promoter of each gene, except for the first CRE (presented as a dark blue box; Fig. 6), which was present twice in the promoter of OsRopGEF2. We predicted that these three CREs will be involved in pollen expression, indicating their functional similarity in the transcriptional regulation process. We analyzed whether these three CREs are conserved in the promoter of AtRopGEF, which is highly expressed in pollen. Although ATRopGEF2 has the first and the third CREs, and ATRopGEF12 has the third CRE, the other pollen-expressed AtRopGEF genes do not contain, indicating that the different regulating system between rice and Arabidopsis might exist. However, OsCrRLK1L13 (LOC_Os06g03610), also known as RUPO (Rupture Pollen tube), possesses these three CREs in promoter regions. RUPO is highly specifically expressed in pollen and is known to regulate pollen-tube growth and integrity in rice [36]. Our results indicate that these three CREs could be candidate for rice pollen-specific gene regulation, and further examination such as deletion assay remains for the clarification of our estimation. Next, using TOMTOM, we revealed that these elements were present in transcription factor genomic sequences such as MYB and bHLH, indicating that the four OsRopGEFs could be regulated in pollen by transcription factors such as MYB, and bHLH, for example.

\section{Plant phenotype of RopGEF mutant}

To determine the function of RopGEF in rice pollen tube growth, we identified a T-DNA insertional lines at T2 generation: $2 \mathrm{~B}-00114$ and $3 \mathrm{~A}-12,915$, having T-DNA within RopGEF6, 3A-00157 and 2A-10,752, having T- 


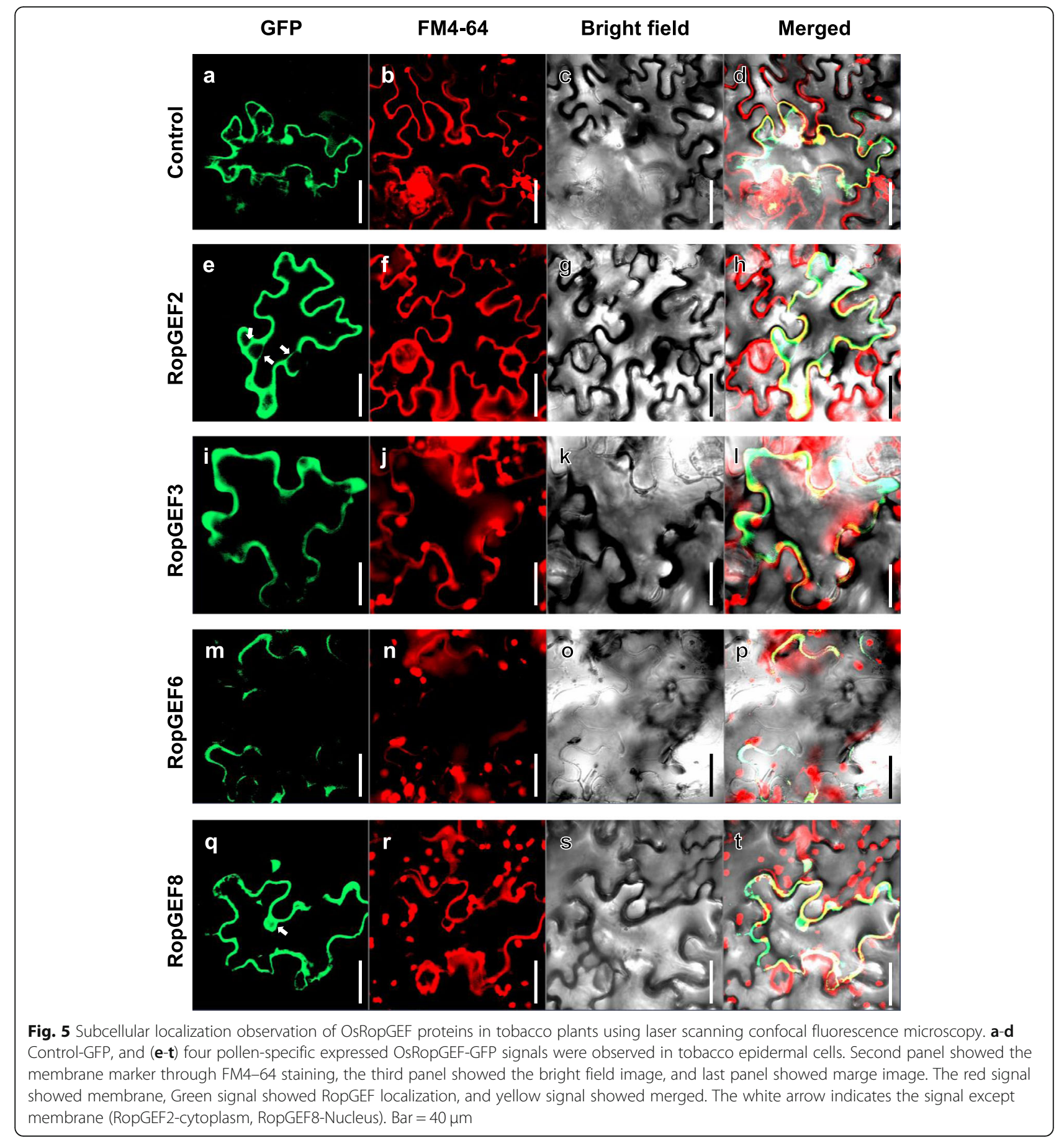

DNA in RopGEF8 and RopGEF2, respectively. Flaking region of about $10 \mathrm{~kb}$ T-DNA insertion was identified into exon region near to $5^{\prime}$ region of genes, indicating their functional gene loss. Therefore, we considered these T-DNA lines as knock-out lines and confirmed the seed segregation ratio. All the single T-DNA insertional lines exhibit normal growth and produce homozygous seed production (Fig. 7a), indicating the male gametic transmission is not disturbed by single gene knock-out, probably due to functional redundancy as shown in Arabidopsis [37]. To confirm it, we used CRISPR/Cas9 system to generate homozygous multiple knock-out mutants at $\mathrm{T}_{0}$ generation [38]. In the knock-out homozygous mutants of RopGEF2, the fertility ratio was slightly reduced but comparable to wild-type. Pollen germination and tube growth did not show difference compared with wild-type plants. In addition, single knockout homozygous mutants of RopGEF3 did not show any 


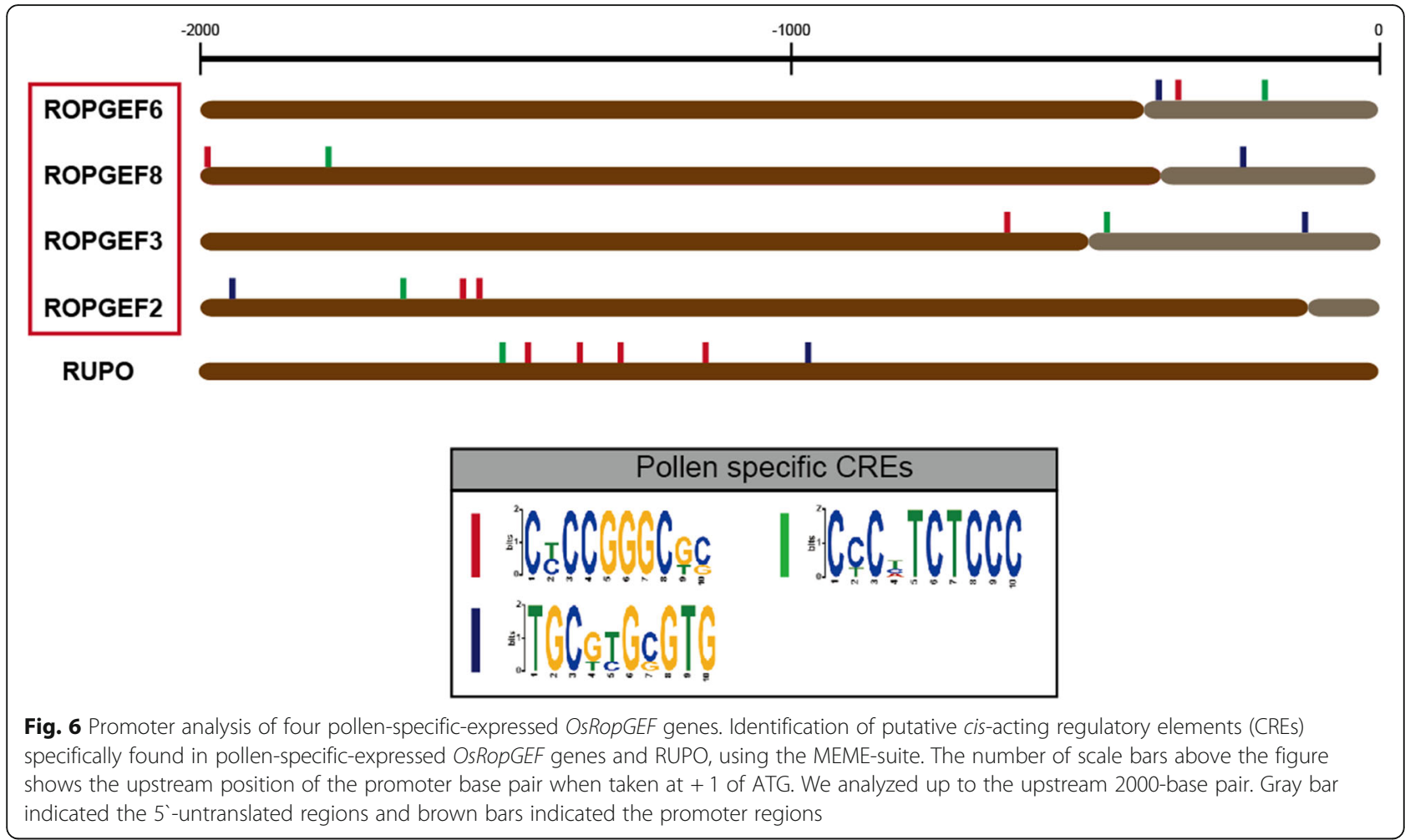

significant changes for growth and seed production, indicating that the male-gametic transmission is normal (Additional file 6).

In contrast, RopGEF2 and RopGEF8 double homozygous bi-allelic plants (ropgef2/8) (Fig. 7a), reduced seed fertility up to $20-30 \%$ compared with wild-type plants (Fig. 7b). There was no significant difference in vegetative and reproductive development between wild type and mutants (Fig. 7c-e). To investigate the possibility of any defect in pollen grain formation, mature pollen grains were examined. The starch formation of mature pollen grains assayed by iodine staining in double knock-out mutant did not differ from that of the wild type (Fig. 7f). To check whether pollen grain formed intact pollen walls, we also stained mature pollen grains with auramine $\mathrm{O}$ and calcofluor white and confirmed no differences between mutant and wild type (Fig. 7g-h). Next, we examined pollen germination behavior of double mutant pollens. Under in vitro pollen germination condition, about $77 \%$ wild-type pollen germinated among $83 \%$ hydrated pollen grains. In contrast, only about $20 \%$ of ropgef $2 /$ 8 double mutant pollens germinated, even though $75 \%$ of the mutant pollens were hydrated (Fig. 7i-k). These data indicate that OsRopGEF genes are functionally redundant for pollen germination in rice. Further different combination of multiple gene mutants could explain functional relationship between four pollen-specific RopGEF genes.

\section{Discussion}

In animal and plant cells, a wide range of key cellular processes that require the establishment of cell polarity are governed by Rho GTPases or ROPs [6, 39, 40]. ROPs transduce intracellular and extracellular stimuli in a spatially and temporally regulated manner, resulting in localized regulation of intracellular responses [6]. The number of ROP proteins varies among plant species: seven in rice, nine in maize, and 11 in Arabidopsis. In Arabidopsis, three ROPS (ROP1, ROP3, and ROP5) are highly expressed in pollen and are functionally redundant in the regulation of pollen tube growth. AtROP1 is localized to the apical region of the pollen tube and is dynamically regulated by endocytosis during pollen tube growth [41, 42]. Disruption of AtROP1 by overexpression of the constitutively active form resulted in swollen tubes whereas disturbance of AtROP1 activation resulted in short pollen tubes $[43,44]$, indicating that the control of ROP activity level is important for pollen tube shape. By contrast, there was no pollen-preferred $R O P$ member in rice, as analyzed by the heatmap of tissue expression (Additional file 7a). Instead, OsRac6, a phylogenetically close member of AtROP1/3/5 (Additional file $7 \mathrm{~b}$ and $\mathrm{c}$ ), was expressed in various tissues including mature anthers and pollen, suggesting that control of ROP activity through control of one member, OsRac6, might be important in rice pollen germination.

To achieve regulation of ROPs, plants might have evolved specific regulators such as RopGEFs [9]. As a 
a

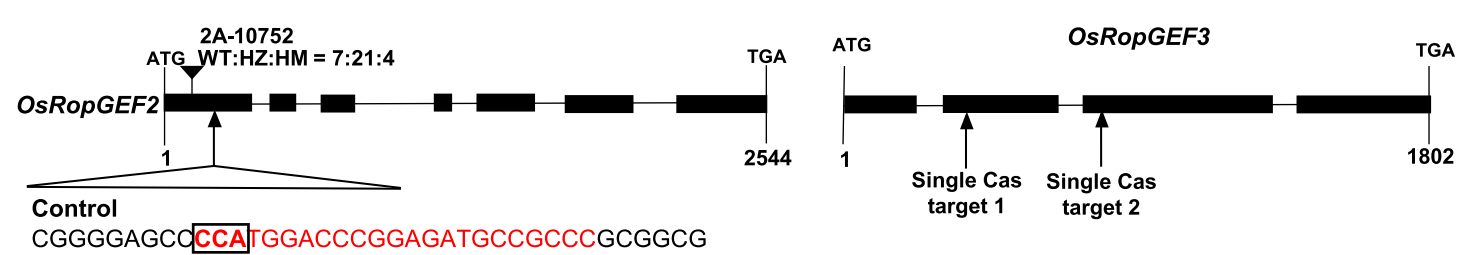

CGGGGAGCOCCATGGACCCGGAGATGCCGCCCGCGGCG

RopGEF2/8 A

ACCCGGAGATGCCGCCCGCGGCG (1bp ins)

CGGGGAGCOCCATGG ----- GAGATGCCGCCCGCGGCG (5bp del)

OsRopGEF6

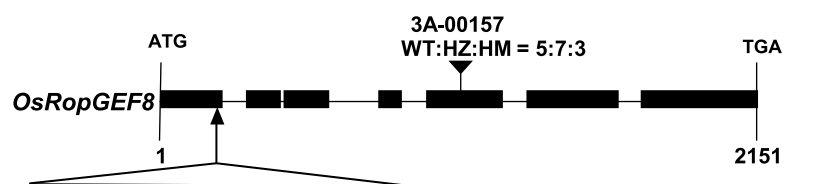

Control

GCGGAGGACCTTCCGGTAAGTCGTCGCCATGATCGAACAC

RopGEF2/8

GCGGAGGACCTTCCGGTA-GTCGTCGCCATGATCGAACAC (1 bp del) GCGGAGGACCTTCCGGTA ---------- GATCGAACAC (12bp del)
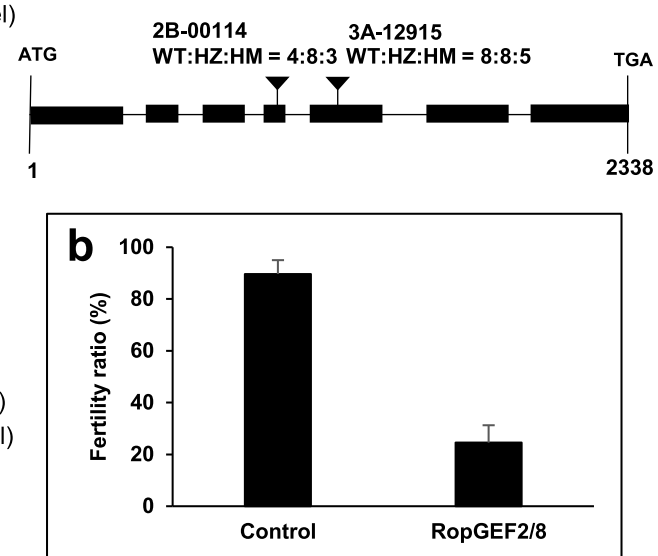

c

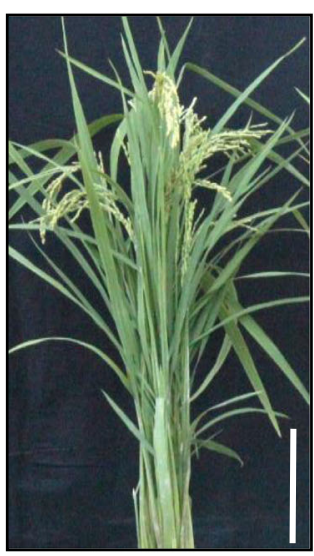

Control

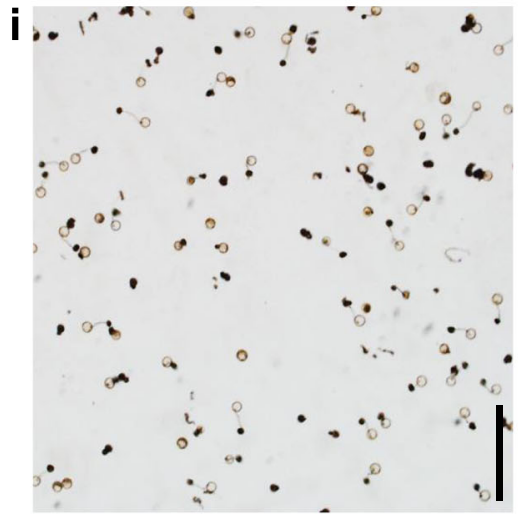

Control

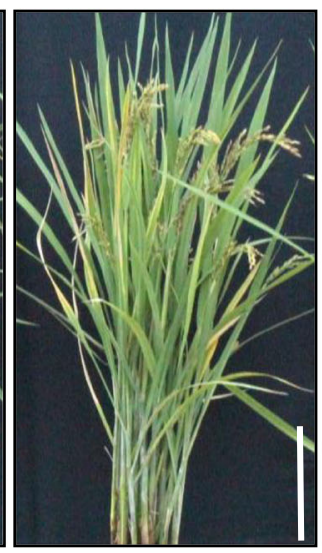

RopGEF2/8

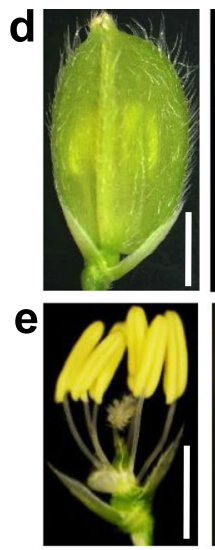

Control

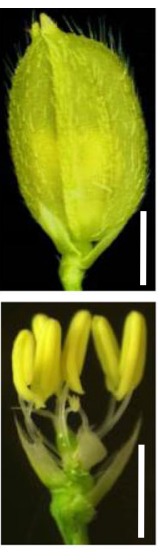

RopGEF2/8
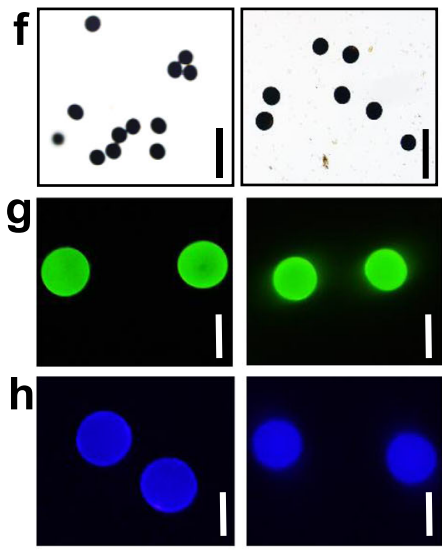

Control

RopGEF2/8
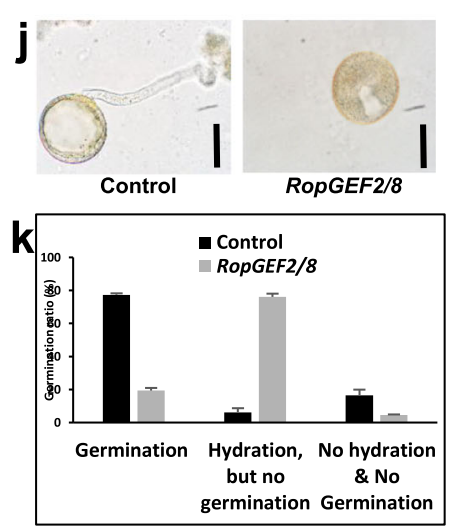

ROPGEF2/8

Fig. 7 (See legend on next page.) 


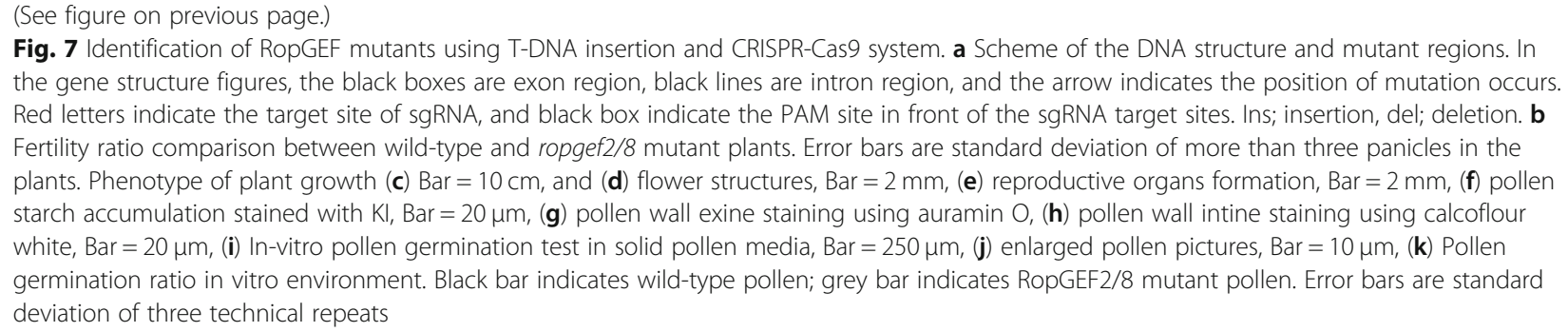

result of comparative expression analysis, we found that four and five genes were highly expressed in pollen among 11 rice and 14 Arabidopsis RopGEF family members, respectively. This suggests that the ROP regulatory mechanism by RopGEF in pollen might be conserved between rice and Arabidopsis. Quadruple mutants of AtRopGEF1, AtRopGEF9, AtRopGEF12, and AtRopGEF14 showed reduced pollen tube elongation, though this effect was not exhibited by any single gene mutation [16]. Due to functional redundancy, single mutants showed no defects in pollen germination and tube growth. Knock-out mutants of OsRopGEF7B were ubiquitously expressed in different tissues, including pollen, causing abnormal development of floral organs but not altered with respect to pollen formation or pollen germination [29]. Instead, OsRopGEF2, OsRopGEF3, OsRopGEF6, and OsRopGEF8 were preferentially expressed in pollen, strongly suggesting their significant roles in pollen germination and tube growth. Our phenotype analysis revealed the defect of pollen germination in generated double homozygous mutant of OsRopGEF2 and OsRopGEF8, reducing fertility ratio, while there is no significant defect on pollen germination in any single mutant. It suggests that rice pollen germination and tube growth require at least two RopGEF genes and there is functional redundancy among RopGEF genes, as in Arabidopsis.

The pollen-preferred expression pattern of the four genes might be explained by the existence of the three cis-acting elements absent from promoters of the other seven, pollen-non-preferred members. Since these cisacting elements also exist in promoters of regulatory genes such as $M Y B$ and $b H L H$, we expect that either MYB or bHLH would be the potential transcription factors regulating the expression of the RopGEFs. However, results from the MEME-suite are required to demonstrate the binding site of the cis-acting elements in promoters of the transcription factors, through further analysis such as the use of the yeast-one hybrid system.

Despite of variable isoforms, gene sequences and protein structures are well conserved throughout AtRopGEFs and OsRopGEFs, especially with respect to the PRONE domain, indicating the conserved activity of the RopGEFs. The differences in the number of alpha helices in the RopGEF 3-D structure may be involved in stabilizing the WW-loop conformation [45]. The 3-D structures of OsRopGEF2 and 6 display the same length of the WW-loop (40 residues) compared with the reported AtRopGEF8 [32], although OsRopGEF3 and 8 exhibit shorter lengths, 34 and 25 residues, respectively (Table 1). The WW-loop is known to be variable in its length and sequence among different members of the RopGEF family [8, 9, $32,45]$. We found that the phosphorylatable serine residue [13] was also conserved in the pollenpreferred OsRopGEFs as in the AtRopGEFs. Further investigations will be required to determine how the four pollen- preferred OsRopGEFs are regulated by interacting partners such as the pollen-preferred RLKs $[17,46]$.

Our report of differential distribution of OsRopGEFs in tobacco epidermal cells indicates that they could regulate different processes of pollen germination. In Arabidopsis, it was observed that RopGEFs interacted differentially with the GTP- and GDP-bound forms of ROP1 and were localized in different subcellular locations [8]. Deletion of the C-terminal domain in AtRopGEF12 abolished the membrane association when it was expressed in tobacco pollen [8]. RopGEFs probably activate ROPs in the PM, and their spatial distribution reflects the sites of ROP activation [6]. It was suggested that the apical location of ROP1 in turn feed-forward regulates exocytosis of RLK and RopGEFs [5]. Another study reported that the phosphorylation of the PRONE domain of RopGEFs by AGC kinase was critical for the localization of RopGEFs to the apical PM, and subsequently for ROP activation and pollen tube polarity [47]. Cellular ROP signaling is also involved in root hair formation, another polar tip-growing plant cell type. Recently, functional analysis revealed that root-hairpreferred AtRopGEF3 functions in root hair initiation by AtROP2 polarization, while another one, AtRopGEF4, regulates subsequent root hair growth [48]. Therefore, it is possible that RopGEF members can be regulated differently by kinases to achieve different localizations and activations, and subsequently function in different phases of polar cell initiation and growth. Further studies of the dynamic distribution of OsRopGEF by other 
signals or interacting partners would provide a better understanding of the molecular network necessary for the process of rice pollen germination.

\section{Conclusions}

Our study identified four genes that are highly expressed in pollen among RopGEF genes in rice, and confirmed their conserved domain in protein sequence, similarity in protein secondary and tertiary structure, and identified each subcellular localization. In addition, we confirm that double knock-out mutant of RopGEF2 and RopGEF8 significantly reduced pollen germination and seed production. We also found a novel cis-regulatory element that is expected to affect pollen expression by promoter analysis and present RopGEF model in the pollen cell. Our study could provide valuable information on the functional study of RopGEF in rice.

\section{Methods}

\section{Multiple sequence alignment and phylogenetic tree} construction

To perform a phylogenetic analysis of RopGEF and $\mathrm{ROP} / \mathrm{Rac}$ in rice and $A$. thaliana, we collected the protein sequences with locus ID from the Rice Genome Annotation Project (http://rice.plantbiology.msu.edu/), the National Center for Biotechnology Information (NCBI, https://www.ncbi.nlm.nih.gov/) and the Phytozome platform (https://phytozome.jgi.doe.gov/pz/portal.html) (Additional file 8). Multiple amino acid sequences were aligned using ClustalW [49]. The phylogenetic analysis was performed using MEGA 7.0.26 under maximum likelihood and neighbor-joining methods [50].

\section{Meta-expression analysis}

We used a publicly available rice Affymetrix microarray data set prepared from diverse tissues include anthers and pollen from the NCBI GEO [51] to identify latepollen-preferred genes (GSE21494, GSE109811, [31]). To examine these data, we used the Affy package encoded by $\mathrm{R}$ language to normalize the signal intensity and then transformed them into $\log _{2}$ values. The normalized data, with averaged Affymetrix anatomical meta-expression data, were then used for further investigations, e.g., heatmap construction, and identification of the late-pollen-preferred genes [52].

\section{Plant growth and RNA extraction}

Rice materials including cv. Dongjin wild type, and TDNA insertion lines used in this study were obtained from T-DNA storage bank in Kyung Hee University (http://signal.salk.edu/RiceGE/RiceGE_Data_Source.html). To grow rice, the seeds were sterilized with $50 \%$ of sodium hypochlorite for $30 \mathrm{~min}$, washed with distilled water, and then germinated on Murashige and Skoog (MS) media under controlled conditions in 7 days $\left(28 / 25^{\circ} \mathrm{C}\right.$ day/night, 8 -h photoperiod, and $78 \%$ relative humidity). The seedlings were grown in the greenhouse for 1 months and then transferred to a paddy field of Kyung Hee University. Plant cultivation and collection of plant materials were performed in accordance with permission and regulation on living modified organism guided by Korean government. For subcellular localization, tobacco (Nicotiana benthamiana) plants were grown as previously described [53] in the growth chamber.

For gene expression analysis, various rice tissues were separately frozen in liquid nitrogen and ground with a Tissue-Lyser II (Qjagen; Hilden, Germany). For pollen isolation, we collected mature pollen in an RNA stabilization solution (RNAlater Tissue Collection; Invitrogen) from dehiscent anther which just started to open. RNA was extracted with TRIzol buffer as follows [54], and cDNAs were synthesized using SuPrimeScript RT premix from GeNet Bio [55]. For tissue -specific expression by qPCR, we used control primer sets for rice ubiquitin 5 (OsUbi5, LOC_Os01g22490). All of the qRTPCR primers we have used in our experiments are listed here (Additional file 9). The PCR cycle conditions used were $95^{\circ} \mathrm{C}$ for $30 \mathrm{~s}, 57^{\circ} \mathrm{C}$ for $30 \mathrm{~s}$, and $72^{\circ} \mathrm{C}$ for $1 \mathrm{~min}$ $30 \mathrm{~s}$ for $22-38$ cycles. For real-time PCR (qPCR), we used cycling conditions of $95^{\circ} \mathrm{C}$ for $15 \mathrm{~s}, 57^{\circ} \mathrm{C}$ for $30 \mathrm{~s}$, and $72{ }^{\circ} \mathrm{C}$ for $60 \mathrm{~s}$ using Roter-Gene $\mathrm{Q}$ instrument system (Qiagen, Hilden, Germany). We used 2x Prime QMastermix (GeNet Bio) which contains SYBR Green1 for qPCR buffer. To determine the significant expression changes of four RopGEF genes in different tissues, we performed $\mathrm{qPCR}$ analysis with three independent biological replicates. Relative transcript levels and fold change were calculated by the $2^{-\Delta C t}$ and $2^{-\Delta \Delta C t}$ methods, respectively [56].

\section{Protein structure analysis}

The three-dimensional (3-D) structural models were computed on a SWISS-MODEL Workspace in a fully automated mode [57] using RopGEF amino acid sequences as templates. The obtained 3-D structures were visualized using the University of California, San Francisco (UCSF) Chimera 1.10 program [58].

\section{Cis-acting elements analysis}

To analyze the pollen-specific promoter regions of four OsRopGEF loci, we extracted 2-kb upstream sequences from the start codon of 11 OsRopGEF loci from EMBL (https://plants.ensembl.org/Oryza_sativa/Info/Index) and Gramene (http://ensembl.gramene.org/Oryza_indica/Info/ Index). To find the cis-elements in the promoter sequences of the OsRopGEF genes, the 2-kb upstream sequence was scanned using the PLACE (Plant cis-acting regulatory DNA elements) database [59]. To discover 
novel motifs, which exist only in pollen-specific RopGEF genes, we performed Multiple Em for Motif Elicitation (MEME)-suite searches with those sequences in the FASTA format via the Web server hosted by the University of Queensland (http://meme-suite.org/tools/meme) [60]. First, we analyzed the 2-kb promoter sequence of all 11 RopGEF genes at once. Next, the 2-kb promoter sequences of the four pollen-specific RopGEF genes were analyzed, and we compared the two data sets using MEME. Among the motifs discovered, we chose those that were found only in the promoter sequence of pollenspecific RopGEF genes and searched for some motifs in databases of known motifs, using TOMTOM. The search conditions were "motif length 5 to 10bp," "indicating only the motifs commonly found in the input data," and "checking both strands."

\section{Subcellular localization analysis}

The coding sequences (CDSs) of four RopGEF genes were amplified from mature anther cDNA and cloned into pGreen vector fused with C-terminal green fluorescence protein (GFP). All of the cloning primers we have used in our experiments are listed here (Additional file 9). The constructs were transfected into A. tumefaciens strain GV3101 and used for Nicotiana benthamiana infiltration as described by [61]. Two to 3 days after infiltration, GFP fluorescence was observed with a confocal laser scanning microscope (Zeiss LSM 510, Jena, Germany) with spectral settings of $500-530 \mathrm{~nm}$ for emission and $488 \mathrm{~nm}$ for excitation. For staining tobacco leaves, the plasma and vacuolar membrane marker FM4-64 (Thermo Fisher Scientific) was used. We treated $0.1 \%$ FM4-64 to tobacco leaves for more than $15 \mathrm{~min}$ in dark condition and observed in red fluorescence protein (RFP) channel in $558 \mathrm{~nm}$ wavelength.

\section{Vector construction and rice transformation}

To design guide RNA for single and multiple Cas vector cloning, we selected two target regions for each locus by CRISPRdirect tool [62]. For CRISPR-Cas9 vector cloning, we synthesized oligo dimers with annealed primers and ligated the dimers with the pRGEB32 binary vector [38]. Ligated vectors were transformed into Escherichia coli, and confirmed the insert by sequencing. After, the plasmid was transformed into the Agrobacterium tumefaciens LBA4404. The transgenic rice plants were generated through the stable transformation via Agrobacterium-mediated co-cultivation [63]. All of the cloning primers we have used in our experiments are listed in Additional file 9.

\section{Phenotype analysis}

For testing phenotypes in mature pollen grains, the starch accumulation was stained with $1 \%$ solution of
Iodine $\left(I_{2}\right)$ and potassium iodide (KI) for $10-20 \mathrm{~min}$. The intine was stained with $0.1 \%$ Calcoflour white for $10 \mathrm{~min}$ and the exine was stained with $0.001 \%$ Auramine $\mathrm{O}$ for $10 \mathrm{~min}$. KI-stained pollen grain was observed with bright field channel, Auramine O-stained pollen grain was observed with Fluorescein isothiocyanate (FITC) channels in $495 \mathrm{~nm}$ wavelength, and Calcoflour whitestained pollen was observed with Ultraviolet (UV) channels in $180 \mathrm{~nm}$ to $400 \mathrm{~nm}$ wavelength. To test in vitro pollen germination, fresh pollen grains were incubated onto a pollen germination medium consisting of $20 \%$ sucrose, $10 \%$ PEG, $3 \mathrm{mM}$ calcium nitrate, $40 \mathrm{mg} / \mathrm{L}$ boric acid, $10 \mathrm{mg} / \mathrm{L}$ vitamin $\mathrm{B} 1$ and $1 \%$ agar. After incubation at $28{ }^{\circ} \mathrm{C}$ for $10-30 \mathrm{~min}$, pollen tubes were observed with a SZX61 microscope (Olympus, Tokyo, Japan).

\section{Supplementary information}

Supplementary information accompanies this paper at https://doi.org/10. 1186/s12870-020-2298-5.

Additional file 1: Figure S1. Meta-expression analysis and genomewide identification of RopGEF in rice. The expressions from various rice tis sues were examined using Microarray database. Yellow color in the heatmap indicates high level of expression; dark blue, low level of expression. Numeric values indicate the average of the normalized $\log 2$ intensity of microarray data.

Additional file 2: Figure S2. Meta-expression analysis of entire AtRopGEF genes. The heatmap was prepared using the Genevestigator. We chose five representative tissues, including pollen. It revealed that five Arabidopsis RopGEFs were highly expressed in pollen. The dark red color of the heatmap indicated the highest expression; white color, lowest expression.

Additional file 3: Figure S3. Protein sequence alignment domain analysis and conserved phosphorylated amino acid residues of C-termini of RopGEF genes. Every OsRopGEF and AtRopGEF protein sequence was collected and aligned, followed by the PRONE domain $(C 1, C 2, C 3)$ and the WW-motif. At the end part of the sequence, we found some conserved regions. According to previous studies, S510 in the C-terminus of AtRopGEF12 is involved in the C-terminal inhibition of GEF activity. As in AtRopGEF12, the serine residue is conserved in each of the OsRopGEF2, OsRopGEF3, and OsRopGEF8 genes but not in OsRopGEF6. However, K (Lysine) can also be phosphorylated.

Additional file 4: Figure S4. Zoom-image of subcellular localization in the tobacco epidermal cells. It shows an enlarged portion of Fig. 5. The first panels in left side showed control and RopGEF proteins' GFP signal, the second panels showed RFP signal stained with the membrane marker FM4-64, the third panels showed bright image, and the last panels on the right indicate merged images. In addition to the membrane signal, the large spot seen in the RFP channel is due to Chlorophyll's auto fluorescence. a-d, Control (pGREEN-GFP); e-h, RopGEF 2; i-l, RopGEF3; m-p, RopGEF6; q-t, RopGEF8. Bars = 10 um.

Additional file 5: Figure S5. Promoter analysis of each OsRopGEF gene. Specific cis-acting element (CRE) known to affect expression in pollen were identified using PLACE database, namely three pollen-CREs and the TATA box. The number above the yellow bar shows the upstream position of the promoter base pair when taken at +1 of ATG. We analyzed up to the upstream 2000-base pair. The $p$-values indicate how significantly the four genes exhibiting high expression in pollen differed from the other seven genes.

Additional file 6: Figure S6. Single mutant assay using CRISPR-Cas9 system. (a-b, d-e) In-vitro pollen germination test of wild-type (a, d), ropgef2 $(b, c)$, and ropgef3 (e-f) single mutants on solid pollen media, Bar = $50 \mu \mathrm{m} ;(c, f)$ enlarged pollen pictures, Bar $=20 \mu \mathrm{m}$. Each control and 
mutant pollen in-vitro assays were performed in the same environment on the same day. $(\mathrm{g})$ The ratio of pollen germination. Black bar indicates wild type; grey bar indicates ropgef2; white bar indicates ropgef3 mutant pollen. Error bars are standard deviation of three technical repeats. (h) Fertility ratio comparison between wild-type and ropgef2 single mutant plants. Error bars are standard deviation of more than three panicles in the plants.

Additional file 7: Figure S7. Meta-expression analysis and genomewide identification of the seven OsRac and ten AtRop genes. (a) Heatmap expression analysis of OsRac gene. (b) Heatmap of AtRop using Genevestigator. (c) Phylogenetic tree constructs including every OsRac and AtRop.

Additional file 8: Table S1. Gene identification of RopGEF genes and RAC/ROP genes.

Additional file 9: Table S2. OsRopGEF isogene-specific primers for qPCR and cloning.

\section{Abbreviations}

CRE: Cis-regulatory elements; CrRLK: Catharanthus receptor-like kinase Dbl: Diffuse B-cell lymphoma; GP: Germinated pollen; GTP: Guanosine triphosphate; MP: Mature pollen; PM: Plasma membrane; PRK: Pollen receptor-like kinase; PRONE: Plant-specific ROP nucleotide exchanger; ROP: Rho-type GTPases of plants; RopGAP: GTPase-activator protein for ROP; RopGEF: Guanine nucleotide exchange factors for ROP; ROS: Reactive oxygen species

\section{Acknowledgements}

Not applicable.

\section{Authors' contributions}

$\mathrm{KHJ}$ and YJK designed the research and acquire funding; KHJ, YJK, EJK, and SWP co-wrote the manuscript and figure arrangement. YJK, EJK, SWP, WJH, and JS performed the experiments and analyzed the data. WL and ZD provided experimental supports and critical comments. All authors have read and approved the final version of the manuscript.

\section{Funding}

This work was supported by the Next-Generation BioGreen 21 Program (PJ01369001 and PJ01366401 to KHJ); and the National Research Foundation of Korea (NRF; 2018R1A4A1025158 and 2019R1C1C1002636 to YJK), funded by the Korean government. The funders had no role in the experiment design, data analysis, decision to publish or preparation of the manuscript.

\section{Availability of data and materials \\ Not applicable.}

\section{Ethics approval and consent to participate}

Not applicable.

\section{Consent for publication}

Not applicable.

\section{Competing interests}

The authors declare that they have no competing interests.

\section{Author details \\ 'Graduate School of Biotechnology and Crop Biotech Institute, Kyung Hee University, Yongin 17104, South Korea. ${ }^{2}$ Joint International Research Laboratory of Metabolic and Developmental Sciences, State Key Laboratory of Hybrid Rice, School of Life Sciences and Biotechnology, Shanghai Jiao Tong University-University of Adelaide Joint Centre for Agriculture and Health, Shanghai Jiao Tong University, Shanghai, China.}

Received: 21 June 2019 Accepted: 20 February 2020 Published online: 04 March 2020

\section{References}

1. Zheng Z, Yang Z. The Rop GTPase: an emerging signaling switch in plants Plant Mol Biol. 2000;44(1):1-9.
2. Akamatsu A, Uno K, Kato M, Wong HL, Shimamoto K, Kawano Y. New insights into the dimerization of small GTPase Rac/ROP guanine nucleotide exchange factors in rice. Plant Signal Behav. 2015;10(7): e1044702.

3. Molendijk AJ, Bischoff F, Rajendrakumar CS, Friml J, Braun M, Gilroy S, Palme K. Arabidopsis thaliana Rop GTPases are localized to tips of root hairs and control polar growth. EMBO J. 2001;20(11):2779-88.

4. Ory S, Gasman S. Rho GTPases and exocytosis: What are the molecular links? Semin Cell Dev Biol. 2011;22(1):27-32. https://doi.org/10.1016/j.semcdb.2010. 12.002. Epub 2010 Dec 8.

5. Luo N, Yan A, Liu G, Guo J, Rong D, Kanaoka MM, Xiao Z, Xu G, Higashiyama T, Cui X. Exocytosis-coordinated mechanisms for tip growth underlie pollen tube growth guidance. Nat Commun. 2017:8(1):1687.

6. Feiguelman G, Fu Y, Yalovsky S. ROP GTPases structure-function and signaling pathways. Plant Physiol. 2018;176(1):57-79.

7. Berken A, Wittinghofer A. Structure and function of rho-type molecular switches in plants. Plant Physiol Biochem. 2008:46(3):380-93.

8. Gu Y, Li S, Lord EM, Yang Z. Members of a novel class of Arabidopsis rho guanine nucleotide exchange factors control rho GTPase-dependent polar growth. Plant Cell. 2006;18(2):366-81.

9. Berken A, Thomas C, Wittinghofer A. A new family of RhoGEFs activates the Rop molecular switch in plants. Nature. 2005;436(7054):1176.

10. Li Z, Liu D. ROPGEF1 and ROPGEF4 are functional regulators of ROP11 GTPase in ABA-mediated stomatal closure in Arabidopsis. FEBS Lett. 2012; 586(9):1253-8

11. Li Z, Waadt R, Schroeder Jl. Release of GTP exchange factor mediated down-regulation of abscisic acid signal transduction through ABA-induced rapid degradation of RopGEFs. PLoS Biol. 2016;14(5):e1002461.

12. Liu Y, Dong Q, Kita D, Huang JB, Liu G, Wu X, Zhu X, Cheung AY, Wu HM, Tao LZ. RopGEF1 plays a critical role in polar Auxin transport in early development. Plant Physiol. 2017;175(1):157-71.

13. Zhang $Y$, McCormick S. A distinct mechanism regulating a pollen-specific guanine nucleotide exchange factor for the small GTPase Rop in Arabidopsis thaliana. Proc Natl Acad Sci U S A. 2007;104(47):18830-5.

14. Kim HU, Cotter R, Johnson S, Senda M, Dodds P, Kulikauskas R, Tang W, Ezcurra I, Herzmark P, McCormick S. New pollen-specific receptor kinases identified in tomato, maize and Arabidopsis: the tomato kinases show overlapping but distinct localization patterns on pollen tubes. Plant Mol Biol. 2002;50(1):1-16

15. Tang W, Kelley D, Ezcurra I, Cotter R, McCormick S. LeSTIG1, an extracellular binding partner for the pollen receptor kinases LePRK1 and LePRK2, promotes pollen tube growth in vitro. Plant J. 2004;39(3):343-53.

16. Chang F, Gu Y, Ma H, Yang Z. AtPRK2 promotes ROP1 activation via RopGEFs in the control of polarized pollen tube growth. Mol Plant. 2013; 6(4):1187-201

17. Yu Y, Song J, Tian X, Zhang H, Li L, Zhu H. Arabidopsis PRK6 interacts specifically with AtRopGEF8/12 and induces depolarized growth of pollen tubes when overexpressed. Sci China Life Sci. 2018;61(1):100-12.

18. Wei LQ, Xu WY, Deng ZY, Su Z, Xue Y, Wang T. Genome-scale analysis and comparison of gene expression profiles in developing and germinated pollen in Oryza sativa. BMC Genomics. 2010;11(1):338.

19. Craddock C, Lavagi I, Yang Z. New insights into rho signaling from plant ROP/Rac GTPases. Trends Cell Biol. 2012;22(9):492-501.

20. Duan Q, Kita D, Li C, Cheung AY, Wu HM. FERONIA receptor-like kinase regulates $\mathrm{RHO}$ GTPase signaling of root hair development. Proc Natl Acad Sci U S A. 2010;107(41):17821-6.

21. Nibau C, Cheung A. New insights into the functional roles of CrRLKs in the control of plant cell growth and development. Plant Signal Behav. 2011;6(5):655-9.

22. Kessler SA, Shimosato-Asano H, Keinath NF, Wuest SE, Ingram G, Panstruga $\mathrm{R}$, Grossniklaus U. Conserved molecular components for pollen tube reception and fungal invasion. Science. 2010;330(6006):968-71.

23. Jamin A, Yang Z. Interactions between calcium and ROP signaling regulate pollen tube tip growth. In: Coding and Decoding of Calcium Signals in Plants. Berlin: Springer; 2011. p. 25-39.

24. Kawasaki T, Imai K, Wong HL, Kawano Y, Nishide K, Okuda J, Shimamoto K. Rice guanine nucleotide exchange factors for small GTPase OsRac1 involved in innate immunity of rice. In: Advances in Genetics, Genomics and Control of Rice Blast Disease. Springer, 2009. p. 179-84.

25. Kawasaki T, Henmi K, Ono E, Hatakeyama S, Iwano M, Satoh H, Shimamoto K. The small GTP-binding protein rac is a regulator of cell death in plants. Proc Natl Acad Sci U S A. 1999;96(19):10922-6. 
26. Liu J, Park CH, He F, Nagano M, Wang M, Bellizzi M, Zhang K, Zeng X, Liu W, Ning Y. The RhoGAP SPIN6 associates with SPL11 and OsRac1 and negatively regulates programmed cell death and innate immunity in rice. PLoS Pathog. 2015;11(2):e1004629.

27. Kosami K, Ohki I, Nagano M, Furuita K, Sugiki T, Kawano Y, Kawasaki T, Fujiwara T, Nakagawa A, Shimamoto K, Kojima C. The crystal structure of the plant small GTPase OsRac1 reveals its mode of binding to NADPH oxidase. J Biol Chem. 2014;289(41):28569-78.

28. Yoo J, Park J, Cho S, Yoo S, Li J, Zhang H, Kim K, Koh H, Paek N. The rice bright green leaf (bgl) locus encodes OsRopGEF10, which activates the development of small cuticular papillae on leaf surfaces. Plant Mol Biol. 2011;77(6):631-41.

29. Huang J, Liu H, Berberich T, Liu Y, Tao L, Liu T. Guanine nucleotide exchange factor 7B (RopGEF7B) is involved in floral organ development in Oryza sativa. Rice. 2018;11(1):42.

30. Kim Y, Zhang D, Jung K. Molecular basis of pollen germination in cereals. Trends Plant Sci. 2019;24(12):1126-36.

31. Moon S, Oo MM, Kim B, Koh H, Oh SA, Yi G, An G, Park SK, Jung K. Genomewide analyses of late pollen-preferred genes conserved in various rice cultivars and functional identification of a gene involved in the key processes of late pollen development. Rice. 2018;11:1-14.

32. Thomas C, Fricke I, Scrima A, Berken A, Wittinghofer A. Structural evidence for a common intermediate in small G protein-GEF reactions. Mol Cell. 2007; 25(1):141-9.

33. Runions J, Brach $T$, Kühner $S$, Hawes $C$. Photoactivation of GFP reveals protein dynamics within the endoplasmic reticulum membrane. J Exp Bot. 2005;57(1):43-50.

34. Shi Y, Liu H, Gao Y, Wang Y, Wu M, Xiang Y. Genome-wide identification of growth-regulating factors in moso bamboo (Phyllostachys edulis): in silico and experimental analyses. PeerJ. 2019;7:e7510.

35. Manimaran P, Reddy MR, Rao TB, Mangrauthia SK, Sundaram R, Balachandran S. Identification of cis-elements and evaluation of upstream regulatory region of a rice anther-specific gene, OSIPP3, conferring pollenspecific expression in Oryza sativa (L.) ssp. indica. Plant reproduction. 2015; 28(3-4):133-42.

36. Liu L, Zheng C, Kuang B, Wei L, Yan L, Wang T. Receptor-like kinase RUPO interacts with potassium transporters to regulate pollen tube growth and integrity in rice. PLoS Genet. 2016;12(7):e1006085.

37. Shin DH, Kim T, Kwon Y, Cho M, Yoo J, Jeon J, Hahn T, Bhoo SH. Characterization of Arabidopsis RopGEF family genes in response to abiotic stresses. Plant Biotechnol Rep. 2009;3(3):183-90.

38. Xie K, Minkenberg B, Yang Y. Boosting CRISPR/Cas9 multiplex editing capability with the endogenous tRNA-processing system. Proc Natl Acad Sci U S A. 2015;112(11):3570-5.

39. Yang Z. Cell polarity signaling in Arabidopsis. Annu Rev Cell Dev Biol. 2008; 24:551-75.

40. Jaffe $A B$, Hall A. Rho GTPases: biochemistry and biology. Annu Rev Cell Dev Biol. 2005;21:247-69.

41. Hwang J, Vernoud V, Szumlanski A, Nielsen E, Yang Z. A tip-localized RhoGAP controls cell polarity by globally inhibiting rho GTPase at the cell apex. Curr Biol. 2008;18(24):1907-16.

42. Li H, Luo N, Wang W, Liu Z, Chen J, Zhao L, Tan L, Wang C, Qin Y, Li C. The REN4 rheostat dynamically coordinates the apical and lateral domains of Arabidopsis pollen tubes. Nat Commun. 2018;9(1):2573.

43. Li H, Lin Y, Heath RM, Zhu MX, Yang Z. Control of pollen tube tip growth by a Rop GTPase-dependent pathway that leads to tip-localized calcium influx. Plant Cell. 1999;11(9):1731-42.

44. Kost B, Lemichez E, Spielhofer P, Hong Y, Tolias K, Carpenter C, Chua NH. Rac homologues and compartmentalized phosphatidylinositol 4, 5bisphosphate act in a common pathway to regulate polar pollen tube growth. J Cell Biol. 1999;145(2):317-30.

45. Thomas C, Fricke I, Weyand M, Berken A. 3D structure of a binary ROPPRONE complex: the final intermediate for a complete set of molecular snapshots of the RopGEF reaction. Biol Chem. 2009:390(5/6):427-35.

46. Löcke S, Fricke I, Mucha E, Humpert M, Berken A. Interactions in the pollenspecific receptor-like kinases-containing signaling network. Eur J Cell Biol. 2010;89(12):917-23.

47. Li E, Cui Y, Ge F, Chai S, Zhang W, Feng Q, Jiang L, Li S, Zhang Y. AGC1. 5 kinase phosphorylates RopGEFs to control pollen tube growth. Mol Plant. 2018;11(9):1198-209.
48. Philipp D, Reichelt A, Schmidt VAF, Mehlhorn DG, Asseck LY, Stanley CE, Keinath NF, Evers JF, Grefen C, Grossmann G. Distinct ROPGEFs successively drive polarization and outgrowth of root hairs. Curr Biol. 2019;29(11):1854-65.

49. Thompson JD, Gibson TJ, Higgins DG. Multiple sequence alignment using ClustalW and ClustalX. Curr Protoc Bioinformatics. 2003;(1):2.3.1-2.3.22.

50. Kumar S, Stecher G, Tamura K. MEGA7: molecular evolutionary genetics analysis version 7.0 for bigger datasets. Mol Biol Evol. 2016;33(7):1870-4.

51. Hong W, Kim Y, Chandran AKN, Jung K. Infrastructures of systems biology that facilitate functional genomic study in rice. Rice. 2019;12(1):15.

52. Nguyen $Q$, Lee $Y$, Cho L, Jeong H, An G, Jung K. Genome-wide identification and analysis of Catharanthus roseus RLK1-like kinases in rice. Planta. 2015;241(3):603-13.

53. Yuan G, Wang Y, Yuan S, Wang P, Duan W, Bai J, Sun H, Wang N, Zhang F, Zhang L. Functional analysis of wheat $\mathrm{TaPaO} 1$ gene conferring pollen sterility under low temperature. J Plant Biol. 2018:61(1):25-32.

54. Kim S, Moon J, Roh J, Kim S. Castasterone can be biosynthesized from 28homodolichosterone in Arabidopsis thaliana. J Plant Biol. 2018;61(5):330-5.

55. Vo KTX, Kim C, Chandran AKN, Jung K, An G, Jeon J. Molecular insights into the function of ankyrin proteins in plants. J Plant Biol. 2015;58(5):271-84.

56. Moon S, Jung K. Genome-wide expression analysis of rice ABC transporter family across spatio-temporal samples and in response to abiotic stresses. J Plant Physiol. 2014;171(14):1276-88.

57. Arnold K, Bordoli L, Kopp J, Schwede T. The SWISS-MODEL workspace: a web-based environment for protein structure homology modelling. Bioinformatics. 2006;22(2):195-201.

58. Pettersen EF, Goddard TD, Huang CC, Couch GS, Greenblatt DM, Meng EC, Ferrin TE. UCSF chimera-a visualization system for exploratory research and analysis. J Comput Chem. 2004;25(13):1605-12.

59. Higo K, Ugawa Y, Iwamoto M, Korenaga T. Plant cis-acting regulatory DNA elements (PLACE) database: 1999. Nucleic Acids Res. 1999;27(1):297-300.

60. Bailey TL, Boden M, Buske FA, Frith M, Grant CE, Clementi L, Ren J, Li WW, Noble WS. MEME SUITE: tools for motif discovery and searching. Nucleic Acids Res. 2009;37(suppl_2):W202-8.

61. Sparkes IA, Runions J, Kearns A, Hawes C. Rapid, transient expression of fluorescent fusion proteins in tobacco plants and generation of stably transformed plants. Nat Protoc. 2006;1(4):2019.

62. Naito $Y$, Hino K, Bono H, Ui-Tei K. CRISPRdirect: software for designing CRISPR/Cas guide RNA with reduced off-target sites. Bioinformatics. 2014; 31(7):1120-3

63. Lee S, Shon Y, Lee SI, Kim CY, Koo JC, Lim CO, Choi YJ, Han C, Chung CH, Ryong Choe Z. Cultivar variability in the agrobacterium-rice cell interaction and plant regeneration. Physiol Plant. 1999;107(3):338-45.

\section{Publisher's Note}

Springer Nature remains neutral with regard to jurisdictional claims in published maps and institutional affiliations.

\section{Ready to submit your research? Choose BMC and benefit from:}

- fast, convenient online submission

- thorough peer review by experienced researchers in your field

- rapid publication on acceptance

- support for research data, including large and complex data types

- gold Open Access which fosters wider collaboration and increased citations

- maximum visibility for your research: over $100 \mathrm{M}$ website views per year

At BMC, research is always in progress.

Learn more biomedcentral.com/submission 